\title{
Fuel cells for electrochemical energy conversion
}

\author{
RyAn P. O'HAYRE \\ Metallurgical and Materials Engineering, Colorado School of Mines \\ 1500 Illinois St, Golden, CO 80401, USA
}

\begin{abstract}
Summary. - This short article provides an overview of fuel cell science and technology. This article is intended to act as a "primer" on fuel cells that one can use to begin a deeper investigation into this fascinating and promising technology. You will learn what fuel cell are, how they work, and what significant advantages and disadvantages they present.
\end{abstract}

\section{1. - What is a fuel cell?}

A fuel cell is essentially a compact electrochemical "factory" that takes fuel as input and produces electricity as output (see fig. 1). Like a factory, a fuel cell will continue to churn out product (electricity) as long as raw material (fuel) is supplied. This is the key difference between a fuel cell and a battery. While both rely on electrochemistry to work their magic, a fuel cell is not consumed when it produces electricity. It is really a factory, a shell, which transforms the chemical energy stored in a fuel into electrical energy.

Viewed this way, combustion engines are also "chemical factories". Combustion engines also take the chemical energy stored in a fuel and transform it into useful mechanical or electrical energy. So what is the difference between a combustion engine and a fuel cell? 


\section{What Is A Fuel Cell?}

\section{- Electrochemical energy conversion device}

- Directly converts chemical energy to electrical energy

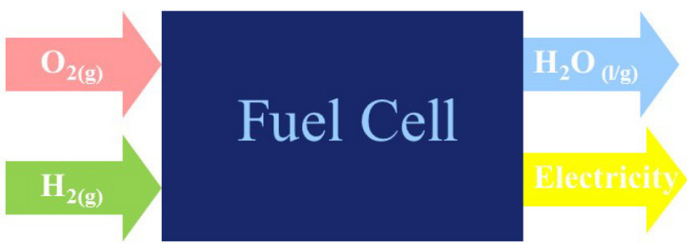

Fig. 1. - General concept of a $\left(\mathrm{H}_{2}-\mathrm{O}_{2}\right)$ fuel cell.

In a conventional combustion engine, fuel is burned, releasing heat. Consider the simplest example, the combustion of hydrogen:

$$
\mathrm{H}_{2}+\frac{1}{2} \mathrm{O}_{2} \rightarrow \mathrm{H}_{2} \mathrm{O}
$$

On the molecular scale, collisions between hydrogen molecules and oxygen molecules result in a reaction. The hydrogen molecules are oxidized, producing water and releasing heat. Specifically, at the atomic scale, in a matter of picoseconds, hydrogen-hydrogen bonds and oxygen-oxygen bonds are broken, while hydrogen-oxygen bonds are formed. These bonds are broken and formed by the transfer of electrons between the molecules. The energy of the product water bonding configuration is lower than the bonding configurations of the initial hydrogen and oxygen gases. This energy difference is released as heat. Although the energy difference between the initial and final states occurs by a reconfiguration of electrons as they move from one bonding state to another, this energy is recoverable only as heat because the bonding reconfiguration occurs in picoseconds at an intimate, subatomic scale. To produce electricity, this heat energy must be converted into mechanical energy, and then the mechanical energy must be converted into electrical energy. Going through all these steps is potentially complex and inefficient.

Consider an alternative solution: to produce electricity directly from the chemical reaction by somehow harnessing the electrons as they move from high-energy reactant bonds to low-energy product bonds. In fact, this is exactly what a fuel cell does. But the question is how do we harness electrons that reconfigure in picoseconds at subatomic length scales? The answer is to spatially separate the hydrogen and oxygen reactants so that the electron transfer necessary to complete the bonding reconfiguration occurs over a greatly extended length scale. Then, as the electrons move from the fuel species to the oxidant species, they can be harnessed as an electrical current. 


\section{How a Fuel Cell Works}

- Spatial and temporal separation of oxidation and reduction reactions

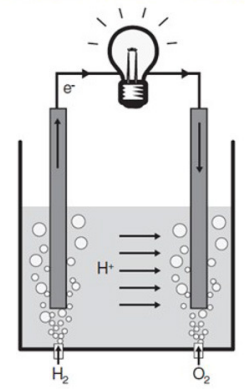

Fig. 2. - A simple fuel cell.

\section{2. - A simple fuel cell}

In a fuel cell, the hydrogen combustion reaction is split into two electrochemical half reactions:

$$
\begin{aligned}
& \mathrm{H}_{2} \rightarrow 2 \mathrm{H}^{+}+2 \mathrm{e}^{-}, \\
& \frac{1}{2} \mathrm{O}_{2}+2 \mathrm{H}^{+}+2 \mathrm{e}^{-} \rightarrow \mathrm{H}_{2} \mathrm{O} .
\end{aligned}
$$

By spatially separating these reactions, the electrons transferred from the fuel are forced to flow through an external circuit (thus constituting an electric current) and do useful work before they can complete the reaction.

Spatial separation is accomplished by employing an electrolyte. An electrolyte is a material that allows ions (charged atoms) to flow but not electrons. At a minimum, a fuel cell must possess two electrodes, where the two electrochemical half reactions occur, separated by an electrolyte.

Figure 2 shows an example of an extremely simple $\mathrm{H}_{2}-\mathrm{O}_{2}$ fuel cell. This fuel cell consists of two platinum electrodes dipped into sulfuric acid (an aqueous acid electrolyte). Hydrogen gas, bubbled across the left electrode, is split into protons $\left(\mathrm{H}^{+}\right)$and electrons following eq. (2). The protons can flow through the electrolyte (the sulfuric acid is like a "sea" of $\mathrm{H}^{+}$), but the electrons cannot. Instead, the electrons flow from left to right through a piece of wire that connects the two platinum electrodes. Note that the resulting current, as it is traditionally defined, is in the opposite direction. When the electrons reach the right electrode, they recombine with protons and bubbling oxygen gas to produce water following eq. (3). If a load (e.g., a light bulb) is introduced along the path of the electrons, the flowing electrons will provide power to the load, causing the light bulb to glow. Our fuel cell is producing electricity! The first fuel cell, invented by William Grove in 1839, probably looked a lot like the one discussed here. 


\section{Fuel Cells vs. Batteries vs. Engines}

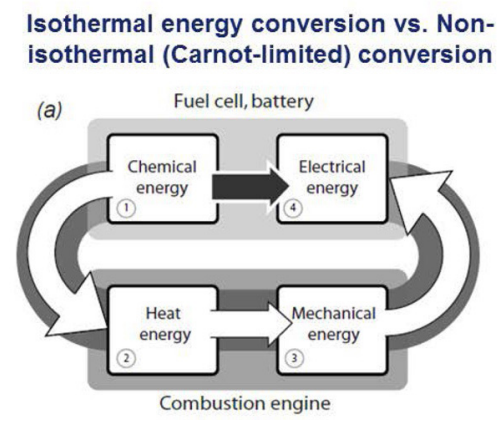

Open vs. Closed System

(b)

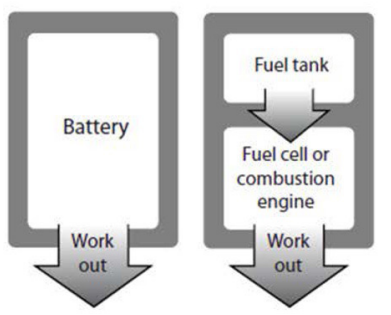

Fig. 3. - Schematic comparison of fuel cells, batteries, and combustion engines. (a) Fuel cells and batteries produce electricity directly from chemical energy. In contrast, combustion engines first convert chemical energy into heat, then mechanical energy, and finally electricity (alternatively, the mechanical energy can sometimes be used directly). (b) In batteries, power and capacity are typically intertwined - the battery is both the energy storage and the energy conversion device. In contrast, fuel cells and combustion engines allow independent scaling between power (determined by the fuel cell or engine size) and capacity (determined by the fuel tank size).

\section{3. - Fuel cell advantages}

Because fuel cells are "factories" that produce electricity as long as they are supplied with fuel, they share some characteristics in common with combustion engines. Because fuel cells are electrochemical energy conversion devices that rely on electrochemistry to work their magic, they share some characteristics in common with primary batteries. In fact, fuel cells combine many of the advantages of both engines and batteries.

Since fuel cells produce electricity directly from chemical energy, they are often far more efficient than combustion engines. Fuel cells can be all solid state and mechanically ideal, meaning no moving parts. This yields the potential for highly reliable and longlasting systems. A lack of moving parts also means that fuel cells are silent. Also, undesirable products such as $\mathrm{NO}_{x}, \mathrm{SO}_{x}$, and particulate emissions are virtually zero.

Unlike batteries, fuel cells allow easy independent scaling between power (determined by the fuel cell size) and capacity (determined by the fuel reservoir size). In batteries, power and capacity are often convoluted. Batteries scale poorly at large sizes, whereas fuel cells scale well from the $1 \mathrm{~W}$ range (cell phone) to the megawatt range (power plant). Fuel cells offer potentially higher energy densities than batteries and can be quickly recharged by refueling, whereas batteries must be thrown away or plugged in for a time-consuming recharge. Figure 3 schematically illustrates the similarities and differences between fuel cells, batteries, and combustion engines. 


\section{4. - Fuel cell disadvantages}

While fuel cells present intriguing advantages, they also possess some serious disadvantages. Cost represents a major barrier to fuel cell implementation. Because of prohibitive costs, fuel cell technology is currently only economically competitive in a few highly specialized applications (e.g., onboard the space shuttle orbiter). Power density is another significant limitation. Power density expresses how much power a fuel cell can produce per unit volume (volumetric power density) or per unit mass (gravimetric power density). Although fuel cell power densities have improved dramatically over the past decades, further improvements are required if fuel cells are to compete in portable and automotive applications. Combustion engines and batteries generally outperform fuel cells on a volumetric power density basis; on a gravimetric power density basis, the race is much closer.

Fuel availability and storage pose further problems. Fuel cells work best on hydrogen gas, a fuel that is not widely available, has a low volumetric energy density, and is difficult to store. Alternative fuels (e.g., gasoline, methanol, formic acid) are difficult to use directly and usually require reforming. These problems can reduce fuel cell performance and increase the requirements for ancillary equipment. Thus, although gasoline looks like an attractive fuel from an energy density standpoint, it is not well suited to fuel cell use.

Additional fuel cell limitations include operational temperature compatibility concerns, susceptibility to environmental poisons, and durability under start-stop cycling. These significant disadvantages will not be easy to overcome. Fuel cell adoption will be severely limited unless technological solutions can be developed to hurdle these barriers.

\section{5. - Fuel cell types}

There are five major types of fuel cells, differentiated from one another by their electrolyte:

1. Phosphoric acid fuel cell (PAFC).

2. Polymer electrolyte membrane fuel cell (PEMFC).

3. Alkaline fuel cell (AFC).

4. Molten carbonate fuel cell (MCFC).

5. Solid-oxide fuel cell (SOFC).

While all five fuel cell types are based upon the same underlying electrochemical principles, they all operate at different temperature regimens, incorporate different materials, and often differ in their fuel tolerance and performance characteristics, as shown in table I. Most of the examples in this book focus on PEMFCs or SOFCs. We will briefly contrast these two fuel cell types.

- PEMFCs employ a thin polymer membrane as an electrolyte (the membrane looks and feels a lot like plastic wrap). The most common PEMFC electrolyte is a 
TABLE I. - Description of major fuel cell types.

\begin{tabular}{|c|c|c|c|c|c|}
\hline & PEMFC & PAFC & $\mathrm{AFC}$ & $\mathrm{MCFC}$ & SOFC \\
\hline Electrolyte & Polymer membrane & $\begin{array}{l}\text { Liquid } \mathrm{H}_{3} \mathrm{PO}_{4} \\
\text { (immobilized) }\end{array}$ & $\begin{array}{l}\text { Liquid } \mathrm{KOH} \\
\text { (immobilized) }\end{array}$ & $\begin{array}{l}\text { Molten } \\
\text { carbonate }\end{array}$ & Ceramic \\
\hline Charge carrier & $\mathrm{H}^{+}$ & $\mathrm{H}^{+}$ & $\mathrm{OH}^{-}$ & $\mathrm{CO}_{3}{ }^{2-}$ & $\mathrm{O}^{2-}$ \\
\hline Operating temperature & $80^{\circ} \mathrm{C}$ & $200^{\circ} \mathrm{C}$ & $60-220^{\circ} \mathrm{C}$ & $650^{\circ} \mathrm{C}$ & $600-1000{ }^{\circ} \mathrm{C}$ \\
\hline Catalyst & Platinum & Platinum & Platinum & Nickel & $\begin{array}{l}\text { Perovskites } \\
\text { (ceramic) }\end{array}$ \\
\hline Cell components & Carbon based & Carbon based & Carbon based & Stainless based & Ceramic based \\
\hline Fuel compatibility & $\mathrm{H}_{2}$, methanol & $\mathrm{H}_{2}$ & $\mathrm{H}_{2}$ & $\mathrm{H}_{2}, \mathrm{CH}_{4}$ & $\mathrm{H}_{2}, \mathrm{CH}_{4}, \mathrm{CO}$ \\
\hline
\end{tabular}

membrane material called Nafion ${ }^{\mathrm{TM}}$. Protons are the ionic charge carrier in a PEMFC membrane. PEMFCs are attractive for many applications because they operate at low temperature and have high power density. As we have already seen, the electrochemical half reactions in a $\mathrm{H}_{2}-\mathrm{O}_{2}$ PEMFC are

$$
\begin{aligned}
& \mathrm{H}_{2} \rightarrow 2 \mathrm{H}^{+}+2 \mathrm{e}^{-}, \\
& \frac{1}{2} \mathrm{O}_{2}+2 \mathrm{H}^{+}+2 \mathrm{e}^{-} \rightarrow \mathrm{H}_{2} \mathrm{O} .
\end{aligned}
$$

- SOFCs employ a thin ceramic membrane as an electrolyte. Oxygen ions $\left(\mathrm{O}^{2-}\right)$ are the ionic charge carrier in an SOFC membrane. The most common SOFC electrolyte is an oxide material called yttria-stabilized zirconia (YSZ). In a $\mathrm{H}_{2}-\mathrm{O}_{2}$ SOFC, the electrochemical half reactions are

$$
\begin{aligned}
& \mathrm{H}_{2}+\mathrm{O}^{2-} \rightarrow \mathrm{H}_{2} \mathrm{O}+2 \mathrm{e}^{-}, \\
& \frac{1}{2} \mathrm{O}_{2}+2 \mathrm{e}^{-} \rightarrow \mathrm{O}^{2-} .
\end{aligned}
$$

To function properly, SOFCs must operate at high temperatures $\left(>600^{\circ} \mathrm{C}\right)$. They are attractive for stationary applications because they are highly efficient and fuel flexible.

Note how changing the mobile charge carrier dramatically changes the fuel cell reaction chemistry. In a PEMFC, the half reactions are mediated by the movement of protons $\left(\mathrm{H}^{+}\right)$, and water is produced at the cathode. In a SOFC, the half reactions are mediated by the motion of oxygen ions $\left(\mathrm{O}^{2-}\right)$, and water is produced at the anode. Note in table I how other fuel cell types use $\mathrm{OH}^{-}$or $\mathrm{CO}_{3}^{2-}$ as ionic charge carriers. These fuel cell types will also exhibit different reaction chemistries, leading to unique advantages and disadvantages. 


\section{How a Fuel Cell Works}

- Electrochemical energy conversion device

- Directly converts chemical energy to electrical energy

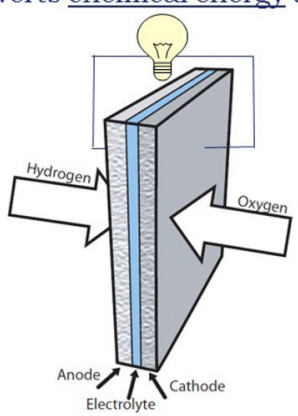

Fig. 4. - Simplified planar anode-electrolyte-cathode structure of a fuel cell.

\section{6. - Basic fuel cell operation}

The current (electricity) produced by a fuel cell scales with the size of the reaction area where the reactants, the electrode, and the electrolyte meet. In other words, doubling a fuel cell's area approximately doubles the amount of current produced.

Although this trend seems intuitive, the explanation comes from a deeper understanding of the fundamental principles involved in the electrochemical generation of electricity. As we have discussed, fuel cells produce electricity by converting a primary energy source (a fuel) into a flow of electrons. This conversion necessarily involves an energy transfer step, where the energy from the fuel source is passed along to the electrons constituting the electric current. This transfer has a finite rate and must occur at an interface or reaction surface. Thus, the amount of electricity produced scales with the amount of reaction surface area or interfacial area available for the energy transfer. Larger surface areas translate into larger currents.

To provide large reaction surfaces that maximize surface-to-volume ratios, fuel cells are usually made into thin, planar structures, as shown in fig. 4. The electrodes are highly porous to further increase the reaction surface area and ensure good gas access. One side of the planar structure is provisioned with fuel (the anode electrode), while the other side is provisioned with oxidant (the cathode electrode). A thin electrolyte layer spatially separates the fuel and oxidant electrodes and ensures that the two individual half reactions occur in isolation from one another. Compare this planar fuel cell structure with the simple fuel cell discussed earlier in fig. 2. While the two devices look quite different, noticeable similarities exist between them.

Figure 5 shows a detailed, cross-sectional view of a planar fuel cell. Using this figure as a map, we will now embark on a brief journey through the major steps involved in producing electricity in a fuel cell. Sequentially, as numbered on the drawing, these steps are as follows: 


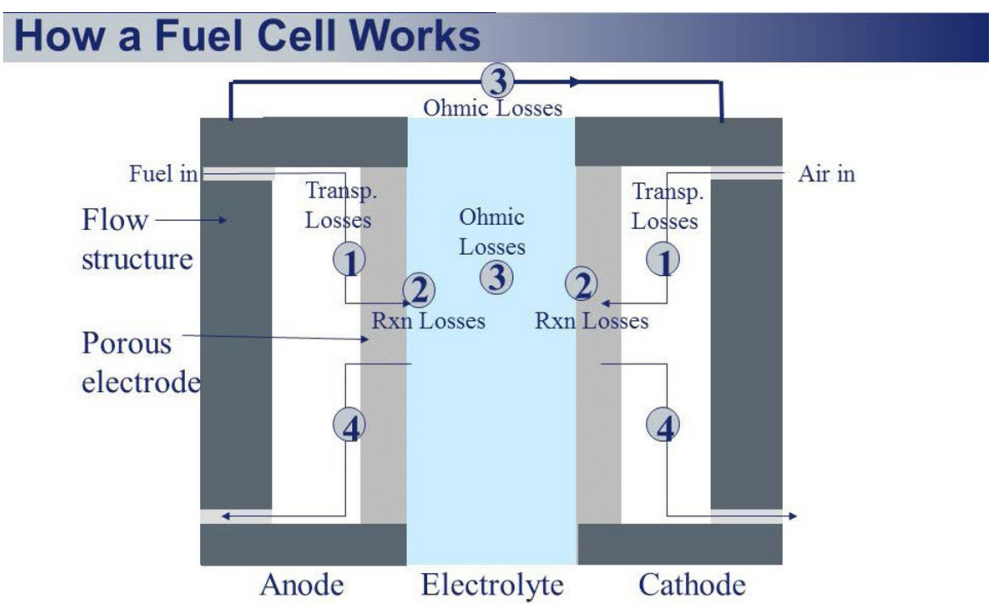

Fig. 5. - Cross-section of fuel cell illustrating major steps in electrochemical generation of electricity: (1) reactant transport, (2) electrochemical reaction, (3) ionic and electronic conduction, (4) product removal.

1. Reactant delivery (transport) into the fuel cell.

2. Electrochemical reaction.

3. Ionic conduction through the electrolyte and electron conduction through the external circuit.

4. Product removal from the fuel cell.

A few further details on each of these steps is provided below:

Step 1: Reactant transport. For a fuel cell to produce electricity, it must be continually supplied with fuel and oxidant. This seemingly simple task can be quite complicated. When a fuel cell is operated at high current, its demand for reactants is voracious. If the reactants are not supplied to the fuel cell quickly enough, the device will "starve." Efficient delivery of reactants is most effectively accomplished by using flow field plates in combination with porous electrode structures. Flow field plates contain many fine channels or grooves to carry the gas flow and distribute it over the surface of the fuel cell. The shape, size, and pattern of flow channels can significantly affect the performance of the fuel cell. Understanding how flow structures and porous electrode geometries influence fuel cell performance is an exercise in mass transport, diffusion, and fluid mechanics. The materials aspects of flow structures and electrodes are equally important. Components are held to stringent materials property constraints that include very specific electrical, thermal, mechanical, and corrosion requirements.

Step 2: Electrochemical reaction. Once the reactants are delivered to the electrodes, they must undergo electrochemical reaction. The current generated by the fuel cell is 
directly related to how fast the electrochemical reactions proceed. Fast electrochemical reactions result in a high current output from the fuel cell. Sluggish reactions result in low current output. Obviously, high current output is desirable. Therefore, catalysts are generally used to increase the speed and efficiency of the electrochemical reactions. Fuel cell performance critically depends on choosing the right catalyst and carefully designing the reaction zones. Often, the kinetics of the electrochemical reactions represent the single greatest limitation to fuel cell performance.

Step 3: Ionic (and electronic) conduction. The electrochemical reactions occurring in step 2 either produce or consume ions and electrons. Ions produced at one electrode must be consumed at the other electrode. The same holds for electrons. To maintain charge balance, these ions and electrons must therefore be transported from the locations where they are generated to the locations where they are consumed. For electrons this transport process is rather easy. As long as an electrically conductive path exists, the electrons will be able to flow from one electrode to the other. In the simple fuel cell in fig. 4, for example, a wire provides a path for electrons between the two electrodes. For ions, however, transport tends to be more difficult. Fundamentally, this is because ions are much larger and more massive than electrons. An electrolyte must be used to provide a pathway for the ions to flow. In many electrolytes, ions move via "hopping" mechanisms. Compared to electron transport, this process is far less efficient. Therefore, ionic transport can represent a significant resistance loss, reducing fuel cell performance. To combat this effect, the electrolytes in technological fuel cells are made as thin as possible to minimize the distance over which ionic conduction must occur.

Step 4: Product Removal. In addition to electricity, all fuel cell reactions will generate at least one product species. The $\mathrm{H}_{2}-\mathrm{O}_{2}$ fuel cell generates water. Hydrocarbon fuel cells will typically generate water and carbon dioxide $\left(\mathrm{CO}_{2}\right)$. If these products are not removed from the fuel cell, they will build up over time and eventually "strangle" the fuel cell, preventing new fuel and oxidant from being able to react. Fortunately, the act of delivering reactants into the fuel cell often assists the removal of product species out of the fuel cell. The same mass transport, diffusion, and fluid mechanics issues that are important in optimizing reactant delivery ( step 1) can be applied to product removal. Often, product removal is not a significant problem and is frequently overlooked. However, for certain fuel cells (e.g., PEMFC) "flooding" by product water can be a major issue.

\section{7. - Fuel cell performance}

The performance of a fuel cell device can be summarized with a graph of its currentvoltage characteristics. This graph, called a current-voltage $(i-V)$ curve, shows the voltage output of the fuel cell for a given current output. An example of a typical $i-V$ curve for a PEMFC is shown in fig. 6. Note that the current has been normalized by the area of the fuel cell, giving a current density (in amperes per square centimeter). Because a larger fuel cell can produce more electricity than a smaller fuel cell, $i-V$ curves are normalized by fuel cell area to make results comparable. 


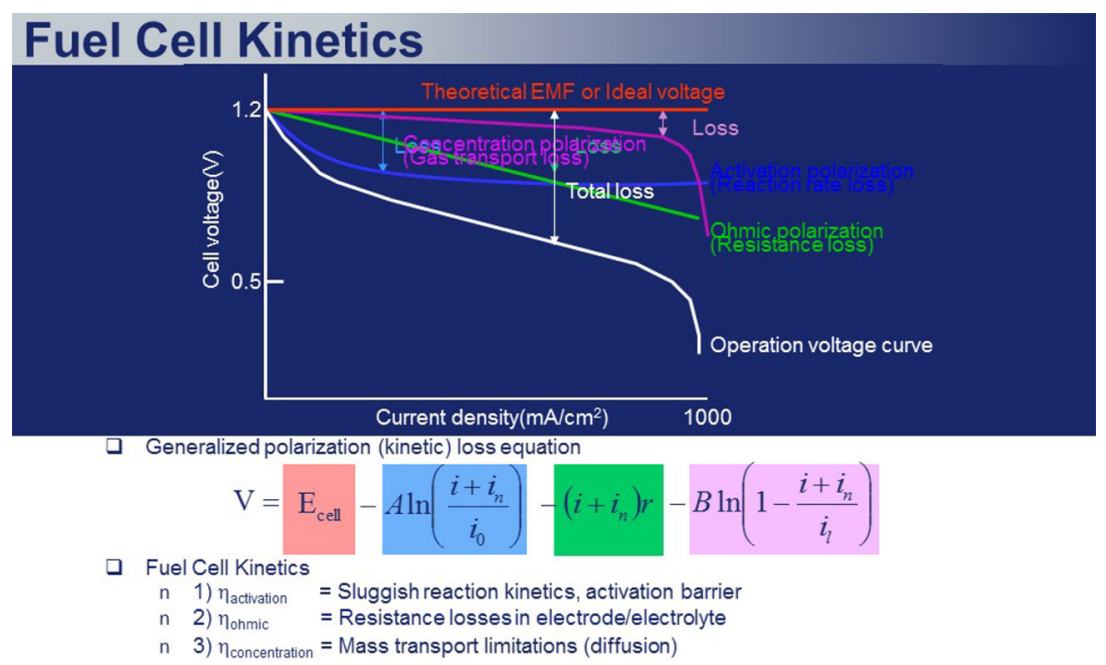

Fig. 6. - Schematic of fuel cell $i$ - $V$ curve. In contrast to the ideal, thermodynamically predicted voltage of a fuel cell (dashed line), the real voltage of a fuel cell is lower (solid line) due to unavoidable losses. Three major losses influence the shape of this $i-V$ curve.

An ideal fuel cell would supply any amount of current (as long as it is supplied with sufficient fuel), while maintaining a constant voltage determined by thermodynamics. In practice, however, the actual voltage output of a real fuel cell is less than the ideal thermodynamically predicted voltage. Furthermore, the more current that is drawn from a real fuel cell, the lower the voltage output of the cell, limiting the total power that can be delivered. The power $(P)$ delivered by a fuel cell is given by the product of current and voltage:

$$
P=i V
$$

A fuel cell power density curve, which gives the power density delivered by a fuel cell as a function of the current density, can be constructed from the information in a fuel cell $i$ - $V$ curve. The power density curve is produced by multiplying the voltage at each point on the $i$ - $V$ curve by the corresponding current density. An example of combined fuel cell $i-V$ and power density curves is provided in fig. 7. Fuel cell voltage is given on the left-hand $y$-axis, while power density is given on the right-hand $y$-axis.

The current supplied by a fuel cell is directly proportional to the amount of fuel consumed (each mole of fuel provides $n$ moles of electrons). Therefore, as fuel cell voltage decreases, the electric power produced per unit of fuel also decreases. In this way, fuel cell voltage can be seen as a measure of fuel cell efficiency. In other words, you can think of the fuel cell voltage axis as an "efficiency axis." Maintaining high fuel cell voltage, even under high current loads, is therefore critical to the successful implementation of the technology. 


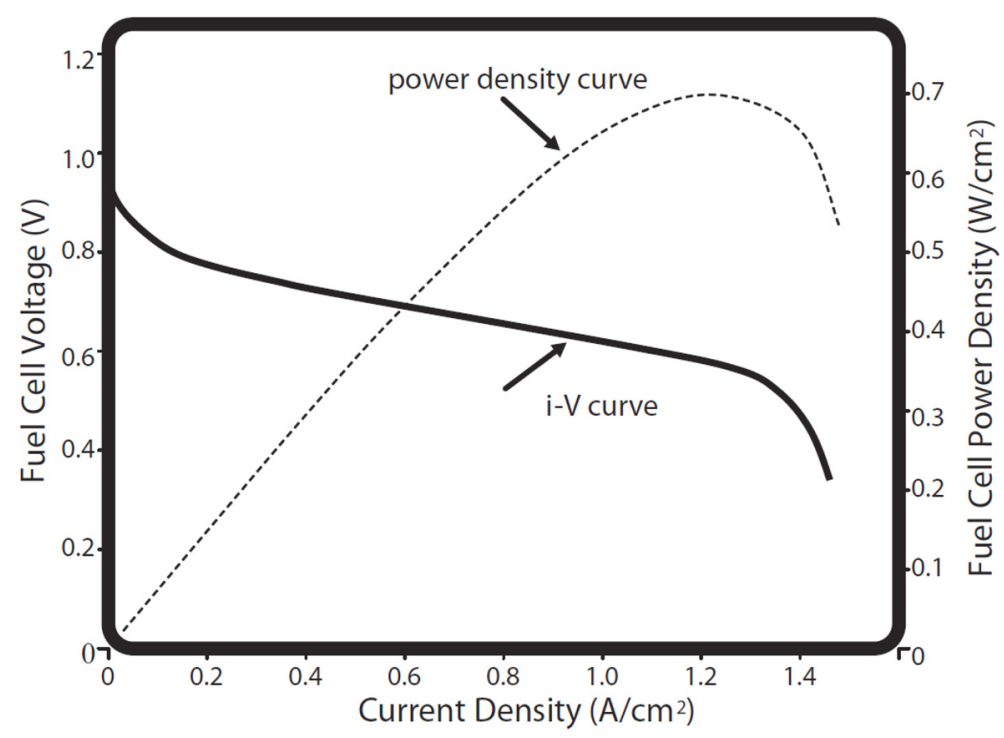

Fig. 7. - Combined fuel cell $i$ - $V$ and power density curves. The power density curve is constructed from the $i$ - $V$ curve by multiplying the voltage at each point on the $i$ - $V$ curve by the corresponding current density. Fuel cell power density increases with increasing current density, reaches a maximum, and then falls at still higher current densities. Fuel cells are designed to operate at or below the power density maximum. At current densities below the power density maximum, voltage efficiency improves but power density falls. At current densities above the power density maximum, both voltage efficiency and power density fall.

Unfortunately, it is hard to maintain a high fuel cell voltage under current load. The voltage output of a real fuel cell is less than thermodynamically predicted voltage output due to irreversible losses. The more current that is drawn from the cell, the greater these losses. There are three major types of fuel cell losses, which give a fuel cell $i$ - $V$ curve its characteristic shape. Each of these losses is associated with one of the basic fuel cell steps discussed in the previous section:

1. Activation losses (losses due to electrochemical reaction).

2. Ohmic losses (losses due to ionic and electronic conduction).

3. Concentration losses (losses due to mass transport).

The real voltage output for a fuel cell can thus be written by starting with thermodynamically predicted voltage output of the fuel cell and then subtracting the voltage drops due to the various losses:

$$
V=E_{\text {thermo }}-\eta_{\text {act }}-\eta_{\text {Ohmic }}-\eta_{\text {conc }}
$$

where

$V=$ real output voltage of fuel cell, 
$E_{\text {thermo }}=$ thermodynamically predicted fuel cell voltage output; set by the laws of thermodynamics,

$\eta_{\text {act }}=$ activation losses due to reaction kinetics,

$\eta_{\text {Ohmic }}=$ Ohmic losses from ionic and electronic conduction,

$\eta_{\text {conc }}=$ concentration losses due to mass transport.

The three major losses each contribute to the characteristic shape of the fuel cell $i$ - $V$ curve. As shown in figs. 6 and 7, the activation losses mostly affect the initial part of the curve; the Ohmic losses are most apparent in the middle section of the curve, and the concentration losses are most significant in the tail of the $i$ - $V$ curve.

\section{8. - Fuel cell technology}

Now that we have briefly overviewed the basic working principles of fuel cells, we will conclude our short introduction of fuel cells with a brief discussion of fuel cell technology.

The first step in the fabrication of a commercial fuel cell device is the production of individual fuel cell "membrane electrode assembly" units or "MEAs". A fuel cell MEA, which consists of an anode electrode, an electrolyte membrane layer, and a cathode electrode, is the basic repeat unit of a fuel cell device. Depending on the type of fuel cell, MEA fabrication can differ significantly. The most common fuel cells are polymer fuel cells (PEMFCs) and solid oxide fuel cells (SOFCs). Figure 8 illustrates the typical steps involved in the fabrication of both PEMFC and SOFC MEAs.

As we have learned, the voltage of a single fuel cell is limited to about 1 V. Furthermore, under load, the output voltage of a single hydrogen fuel cell is typically $0.7-0.8 \mathrm{~V}$. This range generally corresponds to an operational "sweet spot" where the electrical efficiency of the fuel cell is reasonable (around 65\%) and the power density of the fuel cell is near its maximum. However, most real-world applications require electricity at several, tens, or even hundreds, of volts. How do we get $0.7 \mathrm{~V}$ fuel cells to supply the high-voltage requirements of real-world applications? One option is to interconnect multiple fuel cells in series. Connected in series, fuel cell voltages sum. This technique, known as fuel cell "stacking," permits fuel cell systems to meet any voltage requirement.

In addition to building voltage, fuel cell stacks are often designed with these goals in mind:

- Simple and inexpensive to fabricate.

- Low-loss electrical interconnects between cells.

- Efficient manifolding scheme (for reactant gas distribution).

- Efficient cooling scheme (especially for high-power stacks).

- Reliable sealing arrangements between cells. 


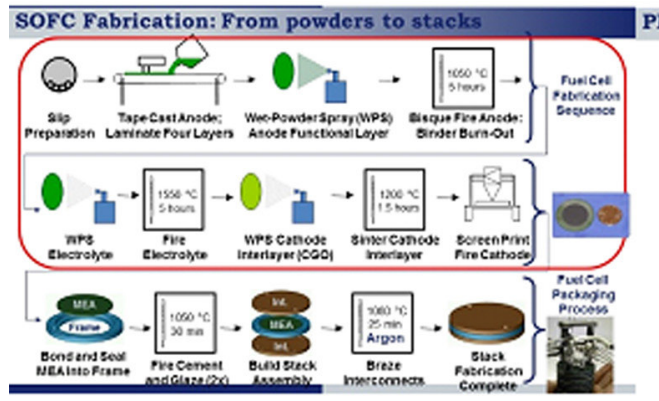

PEMFC Fabrication: From inks to stacks

Fig. 8. - Schematic illustration of the processes involved in fabrication SOFC and PEMFC MEAs.

Figure 9 illustrates a common form of fuel cell stacking, referred to as vertical or bipolar plate stacking. In this configuration, a single conductive flow structure or plate is in contact with both the fuel electrode of one cell and the oxidant electrode of the next, connecting the two fuel cells in series. The plate serves as the anode in one cell and the cathode in the next cell, hence the name bipolar plate. Bipolar stacking is similar to how batteries are stacked on top of one another in a flashlight. Bipolar stacks have the advantage of straightforward electrical connection between cells and exhibit extremely low Ohmic loss due to the relatively large electrical contact area between cells. The bipolar plate design leads to fuel cell stacks that are robust. Most conventional fuel cells stacks adapt this configuration, although other stacking alternatives such as tubular or segmented-in-series designs are also possible.

Beyond simply connecting multiple fuel cell MEAs together in a stack, many other components are required to make a complete fuel cell system. These components include

\section{The first step in scale-up and integration: $1 \mathrm{ACKS}$}

- Typical fuel cell operates at $\sim 0.6$ Volts

- We live in a (minimum) 9-volt world, $240 \mathrm{~V}$ would be nice too

- To achieve target voltage, connect cells in series: STACK

- We stack batteries to use flashlights

- Stacking presents unique packaging challenges

- PEMCs require water management

- SOFCs operate at $600-800^{\circ} \mathrm{C}$

- Combustive gases are present ITN's Fuel Cell Stack
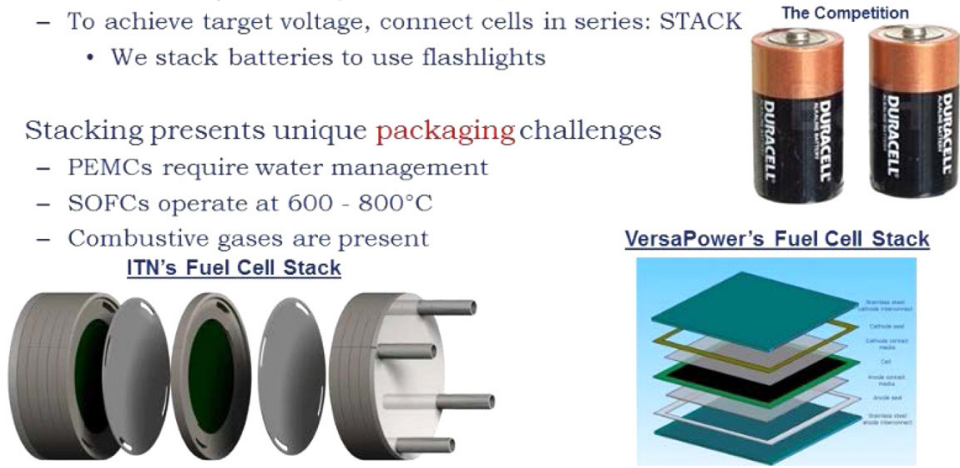

VersaPower's Fuel Cell Stack

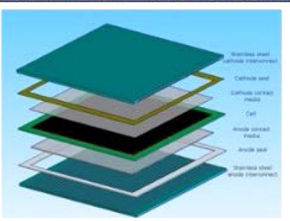

Fig. 9. - Schematic illustration of fuel cell stack design. 


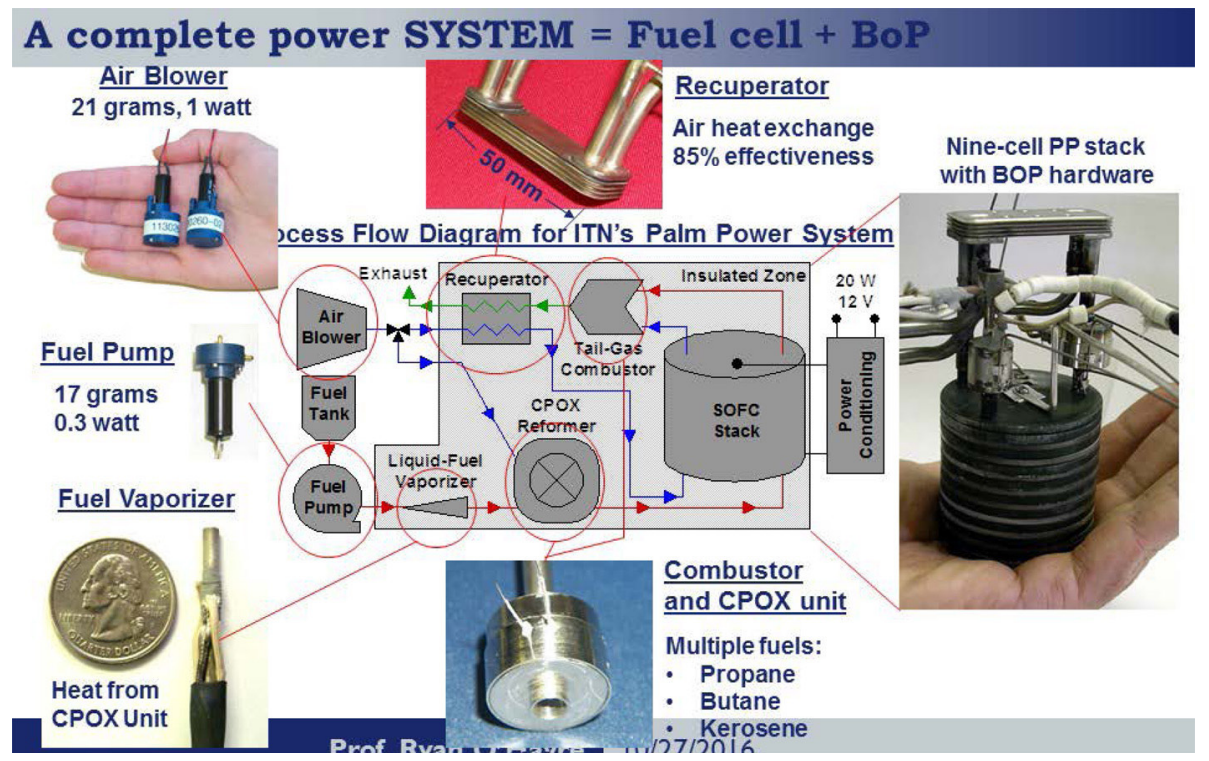

Fig. 10. - Schematic example of the various balance-of-plant components making up a complete portable solid oxide fuel cell system.

devices that provide the fuel supply, cooling, power regulation, and system monitoring, to name a few. Often, these devices, which are collectively known as the Balance of System, or Balance of Plant can take up more room (and cost) than the fuel cell unit itself. Those that draw electrical power from the fuel cell are called ancillaries, or parasitic power devices.

The target application strongly dictates fuel cell system design. In utility-scale stationary power generation, where reliability and energy efficiency are at a premium, there is a strong incentive to include beneficial system components. In portable fuel cell systems, where mobility and energy density are at a premium, there is a strong incentive to minimize system components.

These most common subsystems present in most fuel cell devices include:

- The fuel cell subsystem.

- The thermal management subsystem.

- The fuel delivery/processing subsystem.

- The power electronics subsystem.

Figure 10 provides an example of the type of balance of plant components that might make up a complete portable solid-oxide fuel cell system. Examples of both a large-scale $(220 \mathrm{~kW})$ and a small $(50 \mathrm{~W})$ portable fuel cell system are shown in fig. 11 . In both examples, the fuel cell stack itself takes up less than $30 \%$ of the total size of the system. 

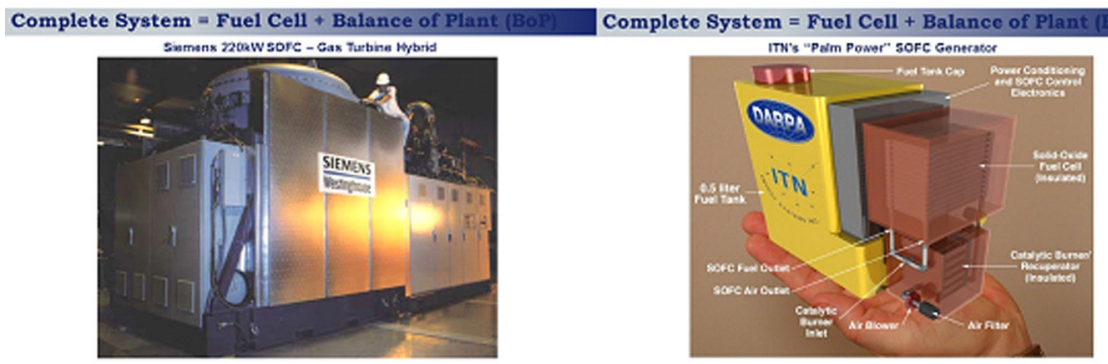

Fig. 11. - Examples of large-scale $(220 \mathrm{~kW})$ and small-scale $(50 \mathrm{~W})$ fuel cell systems.

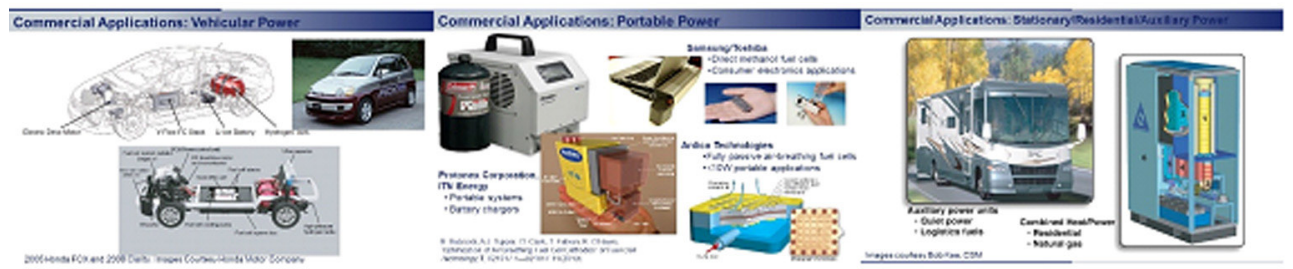

Fig. 12. - Primary fuel cell market opportunities include vehicular, portable, and stationary/distributed power applications.

As illustrated in fig. 12, fuel cells are primarily being considered for use in three main application areas:

- Vehicular applications.

- Stationary/distributed generation applications.

- Portable applications.

Each application area has its own unique requirements and challenges. Although fuel cells have received the most public attention for vehicular applications, in some ways this represents the most challenging market application for fuel cells due to the need for low cost, high durability, extremely high power density, and rapid start-stop cycle capability. Most fuel cell experts believe that portable and stationary (e.g. distributed generation or back-up power) applications offer more attractive near-term opportunities for fuel cell commercialization.

Figure 13 provides two examples of current markets where fuel cells have garnered significant recent success: 1) backup power for remote electronic installations (such as cell-phone towers), and 2) fuel cell powered forklifts for industrial warehouse facilities. In each case, fuel cells offer unique and compelling advantages not available from competing power technologies such as batteries or diesel engines.

Fuel cell technology is truly still in its infancy, and there are significant research challenges that must still be overcome before fuel cells are widely implemented. Decreasing 

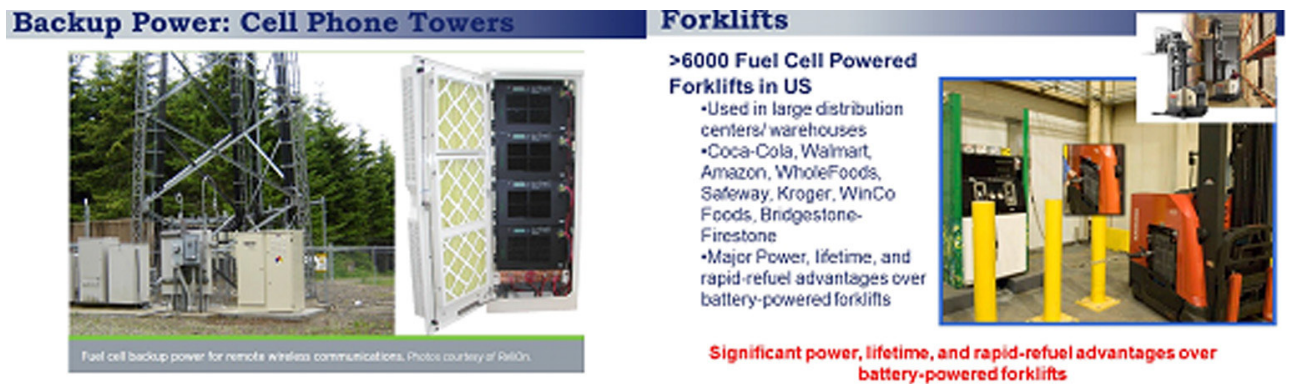

Fig. 13. - Backup power for remote electronic installations (such as cell-phone towers) and fuelcell powered forklifts for warehouse facilities represent two niche markets where fuel cells have gained significant traction.
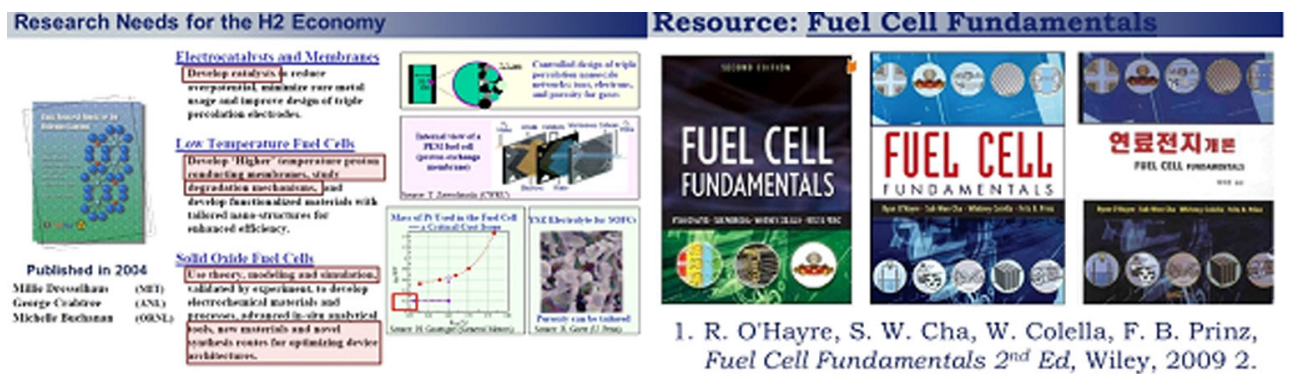

1. R. O'Hayre, S. W. Cha, W. Colella, F. B. Prinz, Fuel Cell Fundamentals $2^{\text {nd }}$ Ed, Wiley, 20092.

Fig. 14. - Suggested resources for further information of the fundamentals of fuel cell science and technology as well as the current major research challenges and opportunities facing the field.

cost, increasing lifetime/durability, and expanding the ability of fuel cells to operate on multiple fuels (beyond hydrogen) represent some of the most important broad-based challenges in the fuel cell research community. For further information on fuel cell science and technology and the research challenges and opportunities facing this field, readers are invited to consult the additional references provided in fig. 14 . 